\title{
Sonar Measurements in Ship Wakes Simultaneous With TerraSAR-X Overpasses
}

\author{
Alexander Soloviev, Mikhail Gilman, Kathryn Young, Stephan Brusch, and Susanne Lehner
}

\begin{abstract}
A pilot experiment was conducted in the period from April to June 2008 in the Straits of Florida near Port Everglades, Florida, in order to study the dynamics of far wakes of ships. In this experiment, a small boat with downward-looking sonar made "snakelike" sections through wakes of ships of opportunity during the TerraSAR-X overpasses. The ship and its parameters (length, speed, course, etc.) were identified utilizing an automated identification system. The sonar responded to the clouds of microbubbles generated in the ship wake by the propulsion system and ship-hull turbulence. The ship wakes were traced in the sonar signal typically from 10 to $30 \mathrm{~min}$ after the ship's passage. A preliminary analysis of the measurements suggests that the visibility of the centerline ship wake in synthetic aperture radar (SAR) images is correlated with the presence of microbubbles in the wake. This supports the hypothesis that natural surfactants scavenged and brought to the surface by rising bubbles play an important role in the wake visibility in SAR. The influence of the wind-wave field on the ship wake, as well as the effect of screening of the wind-wave field by the ship's hull, adds another level of complexity to wake patterns observed in SAR images.
\end{abstract}

Index Terms-Geophysical measurements, remote sensing, sonar imaging, synthetic aperture radar (SAR).

\section{INTRODUCTION}

$\mathbf{T}$ HE PROBLEM of remote detection of ships and ship wakes is related to such important topics as fishing and pollution monitoring, global security, and navigation safety. Ships and ship wakes were discovered to be visible in the first images of the NASA Seasat satellite launched in 1978 [1]. With the recent advances of satellite-based synthetic aperture radar (SAR) technology, interest in remote sensing of ship wakes is increasing. The rapid growth of the number of available SAR platforms could make near-real-time detection of ships from space a reality in a few years.

Manuscript received February 26, 2009; revised July 6, 2009. First published November 10, 2009; current version published January 20, 2010. This work was supported in part by the Nova Southeastern University Oceanographic Center and in part by the German Aerospace Center (DLR). The high-resolution TSX images have been provided under the OCE0143 EXTROP-X proposal (Investigator Dr. Susanne Lehner, DLR).

A. Soloviev is with the Oceanographic Center, Nova Southeastern University, Dania Beach, FL 33004 USA, and also with the Rosenstiel School of Marine and Atmospheric Science, University of Miami, Coral Gables, FL 33124 USA (e-mail: soloviev@ nova.edu).

M. Gilman is with the Oceanographic Center, Nova Southeastern University, Dania Beach, FL 33004 USA (e-mail: gilman@nova.edu).

K. Young was with the Oceanographic Center, Nova Southeastern University, Dania Beach, FL 33004 USA. She is now with Baylor University, Waco, TX 76798 USA (e-mail: ykathryn@ nova.edu).

S. Brusch and S. Lehner are with the Remote Sensing Technology Institute, German Aerospace Center (DLR), 82234 Wessling, Germany (e-mail: stephan.brusch@dlr.de; susanne.lehner@dlr.de).

Digital Object Identifier 10.1109/TGRS.2009.2032053
In SAR images, a ship is usually represented by a bright spot formed by the reflection of the radar signal from the ship's superstructure. In general, a moving ship can generate a wake, which may extend for tens of kilometers. For detection purposes, the ship wake creates additional opportunities because of its size and shape and additional parameters that might be extracted from the image, including direction, speed, and probably some additional information pertaining to the ship (see, e.g., [2]). The topic of ship detection is extensively covered in reviews [3] and [4].

The structure of ship wakes in SAR images is rather complex. Traditional classification specifies ship speckle, Kelvin wake, centerline wake, and other parts of the wake [5], [6]. Often, one or more features of the wake could not be found in the satellite SAR images [5]-[7]. The centerline wake occupies a narrow area extending behind the ship's stern; in SAR images, a centerline wake usually appears as a dark scar. This feature is often the most prominent part of the wake image in SAR [6]. The decrease of radar brightness in the scar is associated with the reduction of surface roughness due to suppression of Bragg-scattering short surface waves by the films of surfaceactive substances (surfactants), wave-current interaction, and turbulence in the wake [8], [9]. Another feature of the centerline wake is its asymmetry with respect to wind direction observed in Seasat SAR images [10] and, more recently, in photo images of ship wakes [11].

The hydrodynamic theory of far centerline wakes of ships, as of today, is comprehended only on a qualitative level (with rare exceptions-see, e.g., [12]). Despite some prominent in situ experiments targeting remote sensing of ship wakes (see, e.g., [9]), the relation between underwater, surface, and electromagnetic processes of SAR imaging of ship wakes is still not completely clear. Acoustic techniques are an effective tool to study ship wakes, which have, however, traditionally been focused mainly on naval applications (see, e.g., [13]-[15]). The use of profiling sonar can give information about bubble clouds in a ship wake and, possibly, turbulence.

In order to improve our understanding of the visibility of ship wakes in SAR images, a pilot experiment was conducted in the period from April to June 2008 by the Nova Southeastern University's Oceanographic Center (NSUOC) and the German Aerospace Center (DLR). In this paper, we present the results of a collection of sea-truth data (sonar echo intensity, weather, and ship operation parameters) simultaneous with SAR imaging in the Straits of Florida. We have been pursuing a hypothesis that the visibility of the centerline ship wake in SAR images is correlated with the presence of microbubbles in the wake. It is generally accepted that, as the bubbles injected into the 

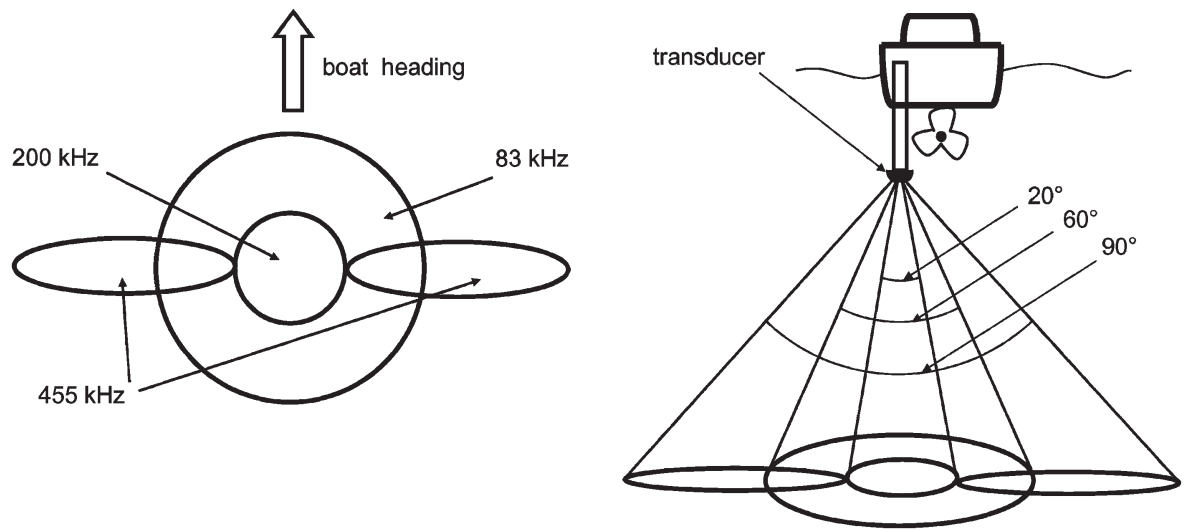

Fig. 1. Geometry of the sonar beams (reproduced from the site www.humminbird.com) and the transducer mounting scheme. (Left panel) Top view. (Right panel) Tail view.

TABLE I

PERTINENT INFORMATION TO THE NSUOC-DLR EXPERIMENT IN THE STRAits OF FLORIDA. Wind INFORMATION IS OBTAINED BY

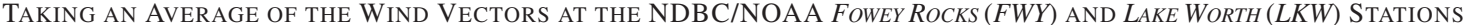

\begin{tabular}{|l|l|l|l|l|l|}
\hline Date (year 2008) & May 23 & May 23 & May 29 & June 09 & June 09 \\
\hline TSX image time & $23: 22: 02$ & $23: 22: 02$ & - & $23: 13: 33$ & $23: 13: 33$ \\
\hline TSX mode & Stripmap & Stripmap & - & Stripmap & Stripmap \\
\hline TSX polarization & VV & VV & - & HH & HH \\
\hline Ship name & Alianca Inca & Xin Su Zhou & Kopalnia Borynia & Eurus Paris & unknown \\
\hline Ship length, m & 148 & 263 & 144 & 148 & - \\
\hline Ship speed, kt & Decelerating to 3 & 16.6 & 11.7 & 11.3 & - \\
\hline Ship heading, deg. & Turning to 45 & 194 & 182 & 140 & - \\
\hline $\begin{array}{l}\text { Wind speed, m/s } \\
\text { (FWY/LKW/averaged) }\end{array}$ & $0.5 / 0.5 / 0.4$ & $0.5 / 0.5 / 0.4$ & $7.7 / 4.1 / 5.9$ & $3.1 / 3.6 / 3.3$ & $3.1 / 3.6 / 3.3$ \\
\hline $\begin{array}{l}\text { Wind Direction, deg. } \\
\text { (FWY/LKW/averaged) }\end{array}$ & $37 / 333 / 5$ & $37 / 333 / 5$ & $72 / 76 / 73$ & $99 / 113 / 106$ & $99 / 113 / 106$ \\
\hline
\end{tabular}

\begin{tabular}{|l|l|l|l|l|}
\hline Date (year 2008) & June 14 & June 14 & June 25 & June 25 \\
\hline TSX image time & $23: 22: 02$ & $23: 22: 02$ & $23: 22: 03$ & $23: 22: 03$ \\
\hline TSX mode & Spotlight & Spotlight & Stripmap & Stripmap \\
\hline TSX polarization & HH & HH & HH & HH \\
\hline Ship name & Enchantment of the Seas & Dole Colombia & MSC Emma & Caribe Legend \\
\hline Ship length, m & 301 & 205 & 294 & 117 \\
\hline Ship speed, kt & 17.6 & 5.3 & 2.1 & 15.2 \\
\hline Ship heading, deg. & 155 & 341 & 172 & 358 \\
\hline $\begin{array}{l}\text { Wind speed, m/s } \\
\text { (FWY/LKW/averaged) }\end{array}$ & $6.7 / 2.6 / 4.6$ & $6.7 / 2.6 / 4.6$ & $9.3 / 4.6 / 6.9$ & $9.3 / 4.6 / 6.9$ \\
\hline $\begin{array}{l}\text { Wind Direction, deg. } \\
\text { (FWY/LKW/averaged) }\end{array}$ & $64 / 74 / 67$ & $64 / 74 / 67$ & $78 / 70 / 75$ & $78 / 70 / 75$ \\
\hline
\end{tabular}

wake by the ship passage and screws rise to the surface, they scavenge and bring along the surfactants dissolved in the sea water [6], [9]. The surface film formed by these surfactants dampens short surface waves. We point out additional factors that affect high-resolution SAR imagery such as wind-wave effects and screening of the wind-wave field by the ship's hull.

\section{INSTRUMENTATION AND METHODOLOGY}

We have been using a sonar producing two downwardlooking beams of 83- and 200-kHz frequency and two separate $455-\mathrm{kHz}$ side-looking beams. The shape of the $83-$ and $200-\mathrm{kHz}$ beams is conical, with $30^{\circ}$ and $10^{\circ}$ cusp half-angle, respectively, whereas the $455-\mathrm{kHz}$ beams are knife-shaped, extending from $10^{\circ}$ to $45^{\circ}$ from the vertical (Fig. 1). The sonar was operated from the Lucy Forman, a 22-ft NSUOC research boat, and the transducer was placed approximately $1.1 \mathrm{~m}$ below the water surface near the boat's stern plane; such configuration of acoustic beams and transducer placement minimizes the effect of the hull and the free surface on the sonar signals. The sonar contour plots in the subsequent sections show the intensity of the reflected sonar signal (hereafter, called "sonar return") in arbitrary decibel units. The signal from the distances of less than $0.8 \mathrm{~m}$ from the transducer has been ignored, which means 


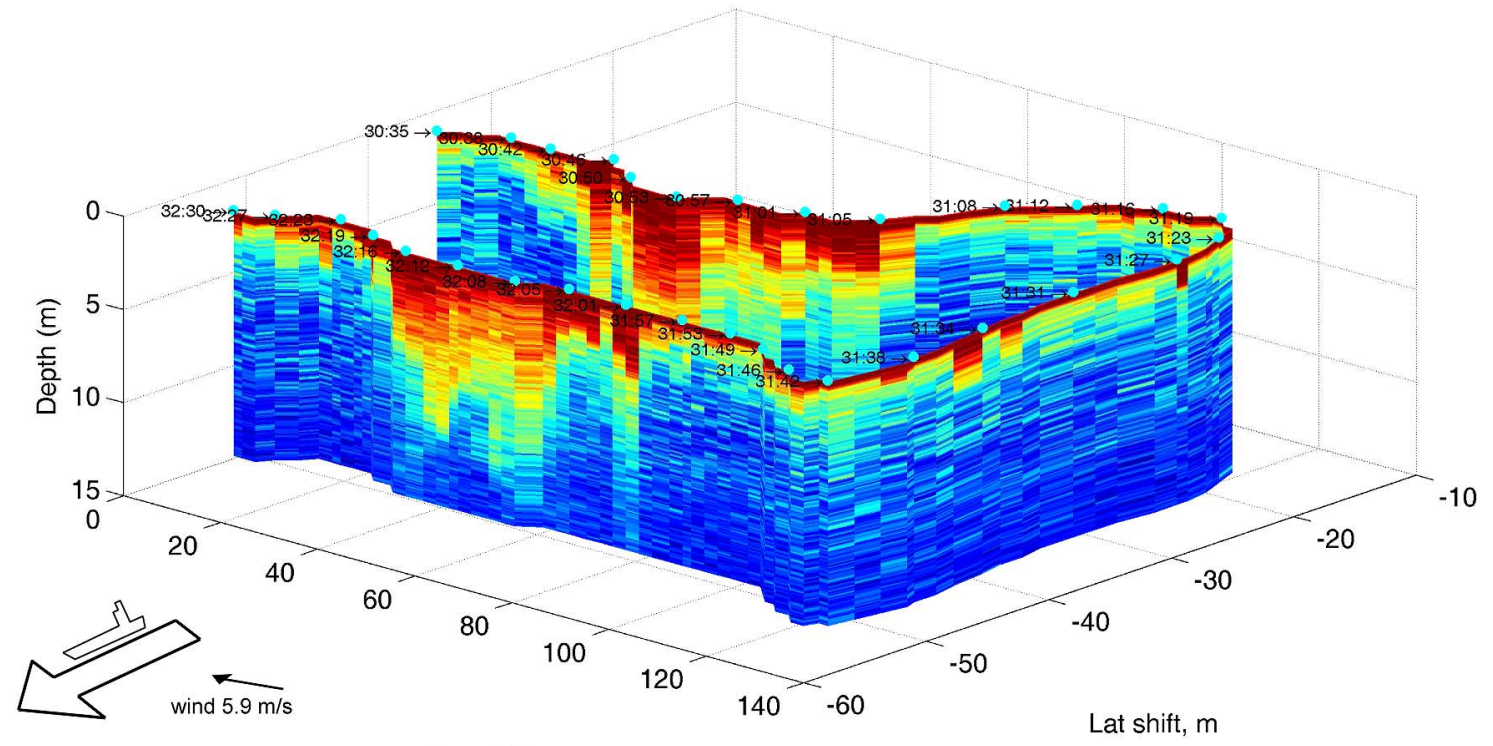

Lon shift, $m$

Fig. 2. Three-dimensional illustration of a part of the boat track and sonar return (beam $200 \mathrm{kHz}$ ) of the wake of Kopalnia Borynia, May 29, 2008, time about 23:30 UTC (minutes and seconds in different points of the track are shown near the markers). The arrows on the left show approximately the ship course and wind direction (see Table I).

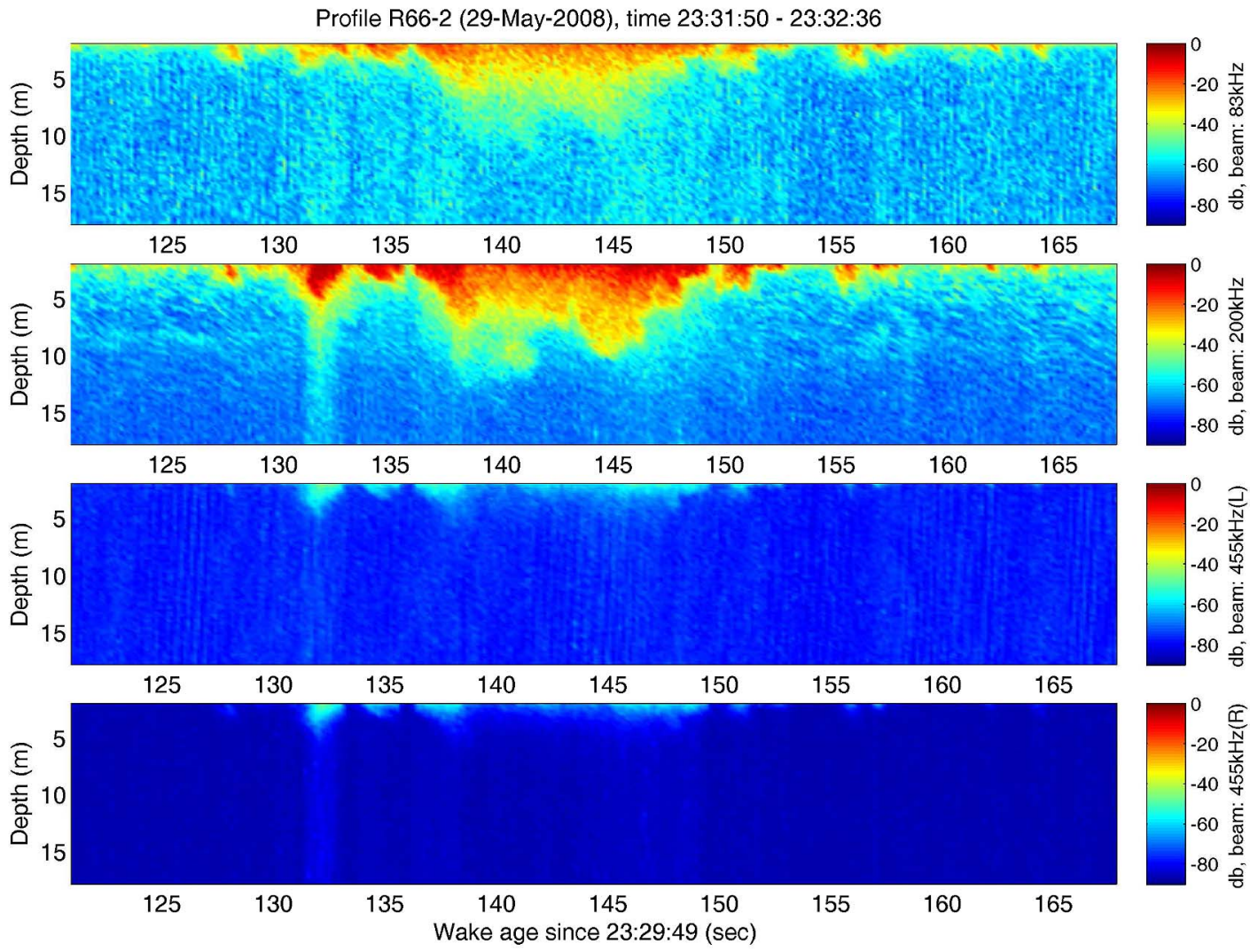

Fig. 3. Sonar return in different frequencies for the second of the wake crossings shown in Fig. 2.

that the sonar data start from approximately 2 -m depth. Even with this gap in the data, the bulk of the wake is captured by the sonar because we have been studying wakes of relatively large ships (upwards of $100 \mathrm{~m}$ in length).

We have been exploring wakes of commercial ships of opportunity in the vicinity of Port Everglades in South Florida.
The ship position and speed were retrieved from the automated identification system (AIS) data using a commercial service. In the area of the experiment, the AIS coverage extends to some $15 \mathrm{mi}$ off the port entrance. In addition, we have tested an alternative to the AIS approach in the determination of ship velocity from the analysis of the TerraSAR-X (TSX) multilook 
data [16]. During the June 9 experiment, this method resulted in a 14-kt ship speed versus 11.75 -kt speed obtained from the AIS (see Table I). Wind information was obtained from the National Data Buoy Center (NDBC)/National Oceanic and Atmospheric Administration (NOAA) weather stations. We have also tested SAR wind retrieval techniques [17] for the June 9 experiment: The SAR wind data were consistent with the interpolated weather buoy data.

The experiment strategy was to cross the ship wake several times on a "snakelike" trajectory at approximately the time of the TSX overpass. Each crossing produced a contour plot of sonar return. With the transducer in the water, the boat moved at the 4- to 5-kt speed, which, with the average wake width 100-200 $\mathrm{m}$ and lifetime 10-60 min, allowed us to make from four to ten full crossings of the wake before the wake dissipated. The intervals between pings were no more than $1 \mathrm{~s}$ for each channel. The boat was run with constant motor power, which, however, resulted in different true speed when moving in different directions with respect to wind and currents. The sonar has a GPS subsystem and writes position and time stamps for each acoustic ping: An example of the sonar data is shown in Fig. 2.

A comparison of wake signatures in different sonar frequencies is shown in Fig. 3. We have found that, of the three frequencies used $(83,200$, and $455 \mathrm{kHz})$, the signature in $200 \mathrm{kHz}$ is the most prominent and long-lived (cf., [18]); this channel is used throughout the rest of this paper. In terms of resonant bubble sizes, the aforementioned frequencies at the depth of $5 \mathrm{~m}$ correspond to the bubble radius of approximately 50, 20, and $10 \mu \mathrm{m}$, respectively. The pattern of the acoustic wake signatures in our experiment is also similar to the experimental data in [19] obtained using an autonomous underwater vehicle. Bubbles of different sizes in ship wakes have been the subject of many publications (see, e.g., [19] and references therein). According to Shen and Lemmin [18], the intensity of the sonar return could be used to estimate the dissipation rate of turbulent kinetic energy due to the mechanism of acoustic Bragg scattering in the scale of the wavelength. However, this technology is still under development and has not been utilized in our studies.

\section{MEASUREMENTS}

\section{A. Overview}

During the experiments, the main challenge was to find a ship of opportunity that, during the TSX acquisition, would be on the image footprint, within the AIS area, and within the reach of the sonar-equipped boat. In some cases, adverse weather conditions or boat operation logistics prevented us from making sonar measurements during the TSX satellite overpasses. In a few cases, the TSX images could not be taken during the sonar measurements because of scheduling conflicts. In three cases (from the total of 12 attempts during this pilot experiment), the in situ measurements in the wake of a ship of opportunity and the TSX images overlapped in time and space:

1) May 23: decelerating and turning ship; TSX polarization is VV;

2) June 9: steadily moving ship; polarization: $\mathrm{HH}$;

3) June 25: drifting ship; polarization: $\mathrm{HH}$.
(The abbreviation VV stands for vertical transmit and receive polarization and $\mathrm{HH}$ for horizontal transmit and receive polarization.)

Pertinent information to these and other cases analyzed in this paper is given in Table I.

\section{B. Steadily Moving Ship (TSX Polarization HH)}

Fig. 4 shows the TSX image (left panel) and the simultaneous sonar measurements (right panel) in the wake of the Eurus Paris container ship on June 9, 2008. The wake is clearly seen in the SAR image. Four wake crossings with sonar were made while the wake could be resolved in acoustic imagery. In the SAR image, the equivalent aft distance for each of the sonar contour plots is schematically shown by the rectangles. This distance has been estimated using the ship speed and the time since the ship's passage.

Fig. 5 (left panel) shows the same SAR image of the wake of the Eurus Paris in range-azimuth coordinates, and Fig. 6 shows the sonar contour plots in more detail. In the sonar images (Fig. 6), we can see that, as the wake ages, its acoustic signature widens, weakens, and splits into several clusters. In the far wake, the edges of the acoustic signature might be associated with the thin dark lines along the ship track in the SAR image (Fig. 5, left panel). These elusive features are usually found in SAR images under low wind speed conditions and are called "railroad track" by some authors [9]. Similar patterns could also be seen in the far wake of another ship in the same SAR image (Fig. 5, right panel).

A prominent feature of both ship wakes shown in Fig. 5 is the wake asymmetry with respect to the wind direction: A bright line could be seen on the upwind side of the centerline wake. No distinct wind asymmetry has been found in sonar imagery though. Apparently, the processes that are ultimately responsible for the local variations of surface roughness, such as modification of short waves on the upwind side of the wake and dampening due to films and turbulence, are concentrated in the top layer of the water and could not be "observed" by a downward-looking sonar.

Sonar observations of ship wakes made in [14] and [20] demonstrate that, at some distance astern of the ship, the acoustic wake splits into two parts. In our experiments, however, we cannot always isolate two distinct parts of the wake's acoustic signature. The difference may be due to many factors, including different weather conditions and the type and size of the ships.

\section{Decelerating Ship (TSX Polarization VV)}

Just before the imaging time on May 23, 2008, the ship Alianca Inca was moving in the south-southwest direction with reducing speed; then, it made a sharp U-turn to the left and finally stopped. At the time of the TSX image, the ship has almost completed the turn and headed northeast (Fig. 7, center panel).

Although the wake of this ship is very faint on the TSX image in Fig. 7 (center panel), the acoustic signature of the wake is prominent (Fig. 8). The main acoustic features of this wake are essentially the same as for the case of a steadily moving ship 

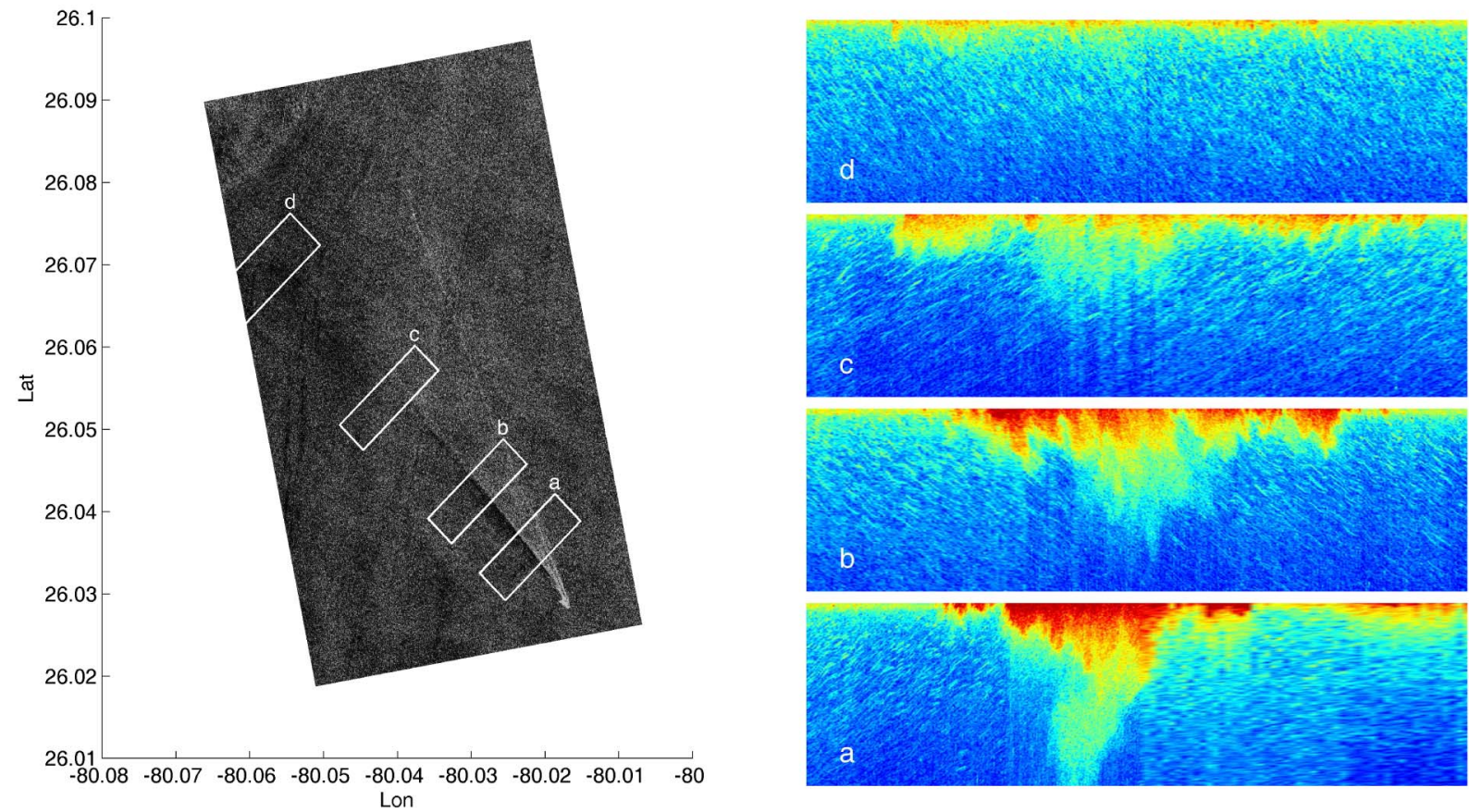

Fig. 4. (Left) SAR image of the wake of a moving ship, Eurus Paris (June 9, 2008). The rectangles on the image show the wake areas with wake age corresponding to the four crossings of the wake, which are shown in the right panel and in Fig. 6. (Right) Plots of the sonar return; the panels for east-towest crossings ( $\mathrm{a}$ and $\mathrm{c}$ ) are flipped horizontally to achieve the same "geographical" orientation of all four panels. The depth ranges from approximately 2 to $18 \mathrm{~m}$ (for more details, see Fig. 6).
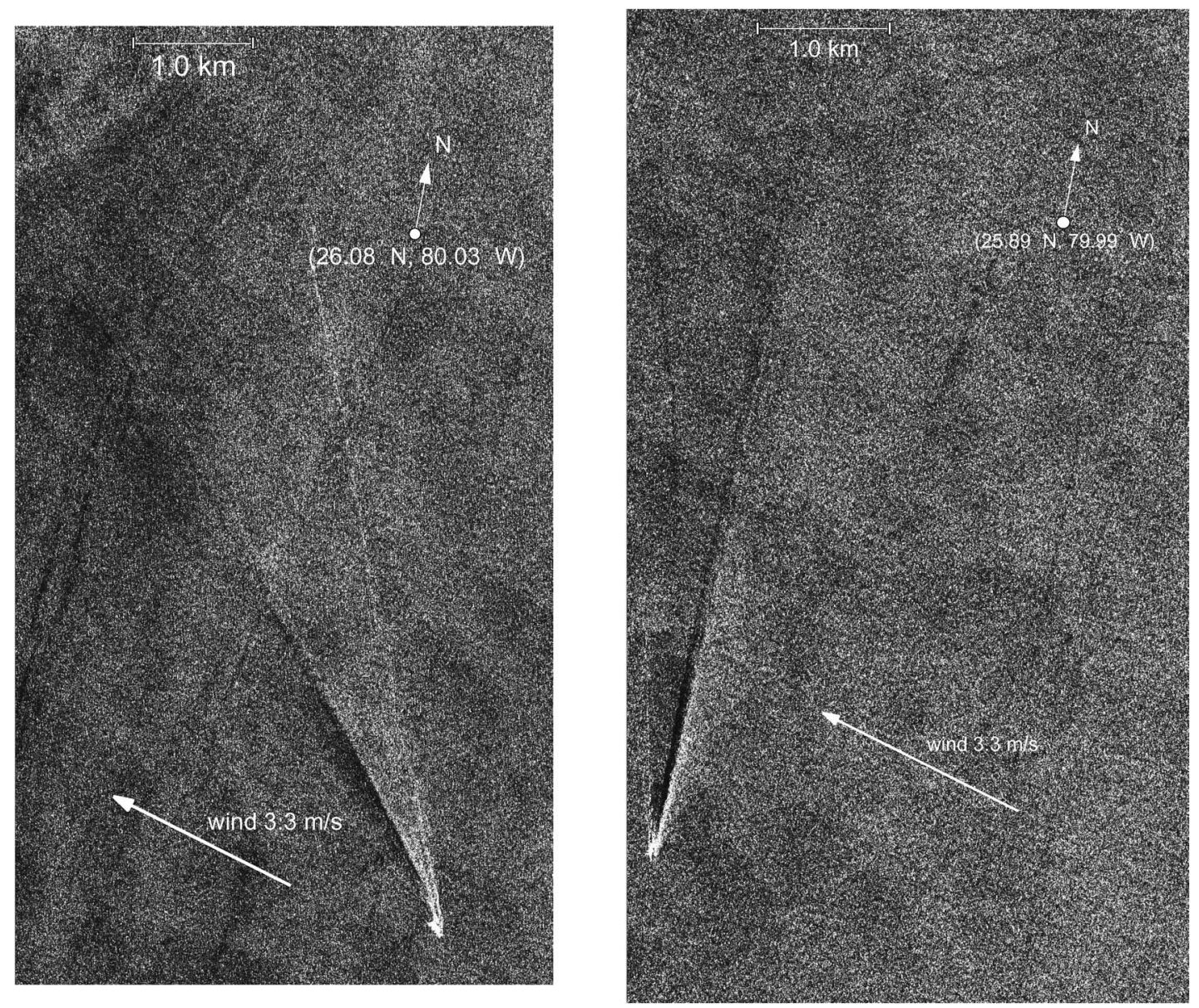

Fig. 5. Asymmetry of the centerline ship wake: Clips from the TSX image on June 9, 2008 (in range-azimuth coordinates). (Left) Close-up of the wake of Eurus Paris. (Right) Wake of another ship in the same area (the ship identity and parameters are unknown). The problem of visibility of different arms of the Kelvin wakes is discussed in detail in [7]. 

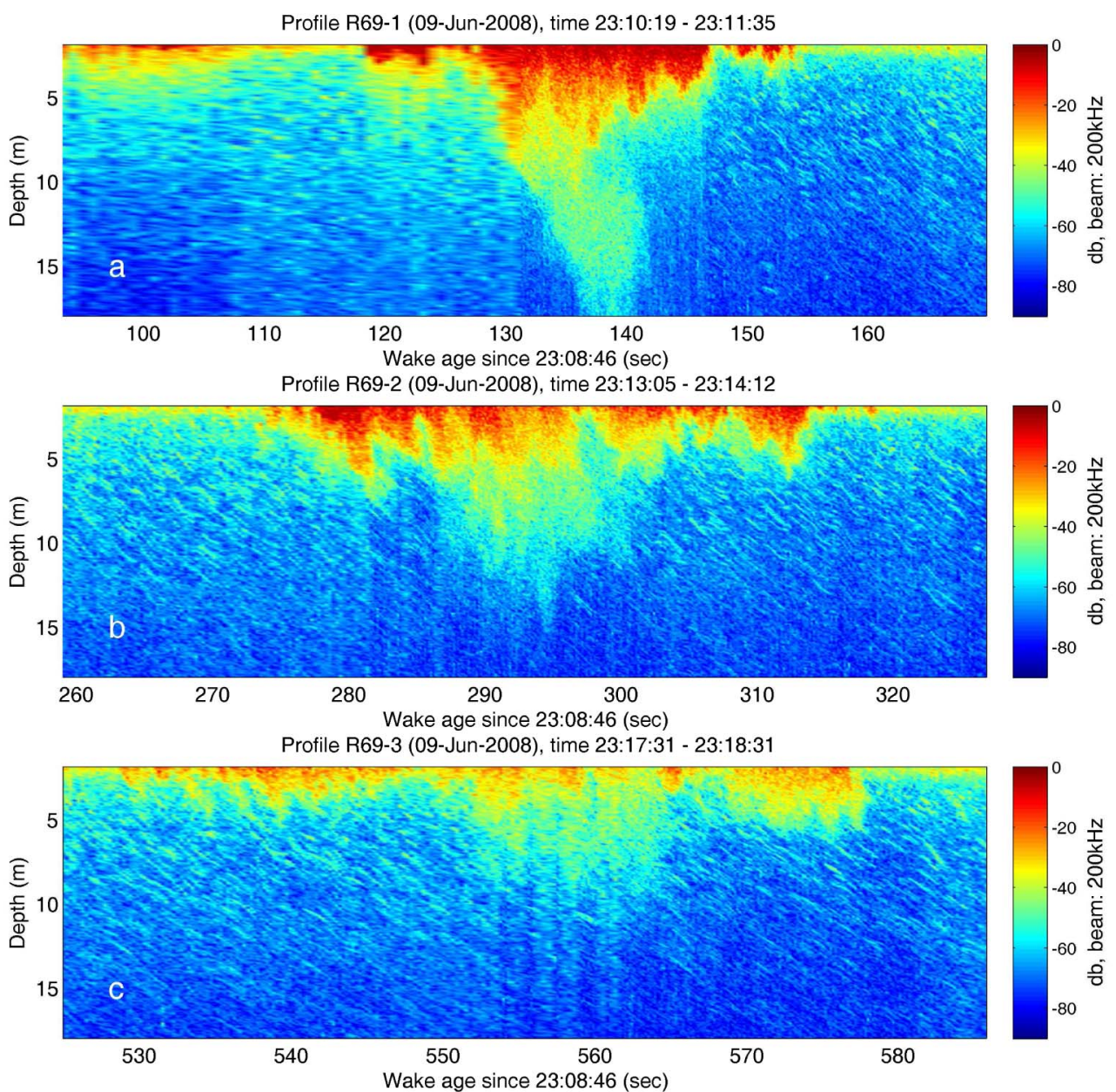

Profile R69-4 (09-Jun-2008), time 23:23:11 - 23:24:59

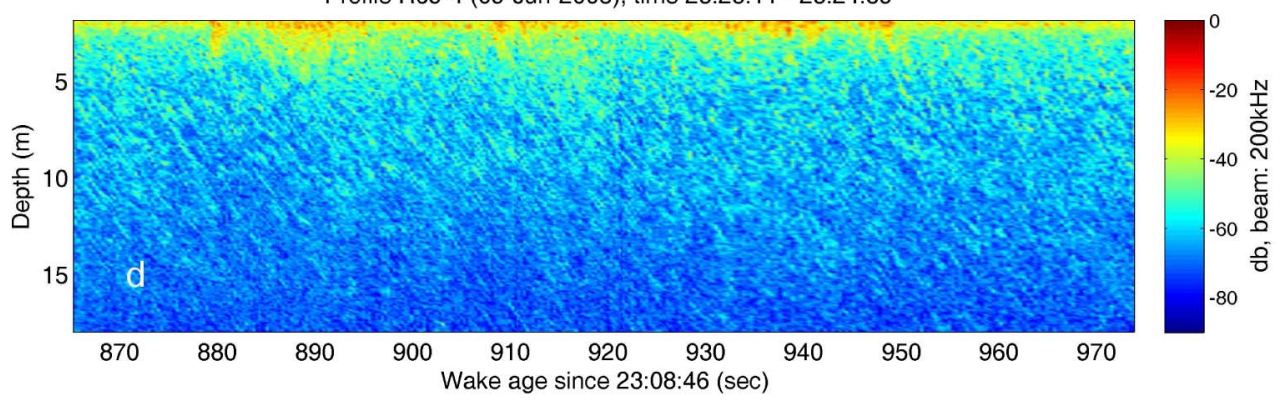

Fig. 6. Four crossings of the wake of a moving ship on June 9, 2008. The "smeared" appearance of the plot from 95 to $130 \mathrm{~s}$ is due to larger speed of the observation platform.

analyzed in Section III-B. The initial tilt of the wake signature in the sonar image is most likely due to the ship turning; it can barely be seen after the first three crossings of the wake (Fig. 8).

The low contrast of this wake in the SAR image could, in part, be explained by very low wind speed, proximity to the shore, and VV polarization. We may argue that, since the area around the decelerating ship was very calm (probably already slick-covered), the contrast of the slick due to the ship passage was low. There are different opinions about the polarization that is most favorable for detection of ship wakes (see, e.g., [3], [4], [21], and [22]); however, the analyses were mostly made for previous-generation SAR satellites with 20- to 30-m resolution and need yet to be reviewed for higher resolution imagery. Our experience thus far (which we cannot confirm quantitatively yet) is that $\mathrm{HH}$ polarization is better for ship wake detection than VV polarization. One hint for the possible explanation could be found in [23], where wave breaking is considered to be an important mechanism that is responsible for radar contrast of hydrodynamic features. If, according to that theory, the input from wave breaking is similar for both polarizations while the background scattering is much lower for $\mathrm{HH}$ polarization, then the contrast due to wave-breaking zones for $\mathrm{HH}$ polarization should be higher. Note that the wake of a steadily moving ship in the same image (Fig. 7, right panel) can be seen better: The distance from the shore to the second wake is almost twice that of the first wake, and the background there is not so dark, so 

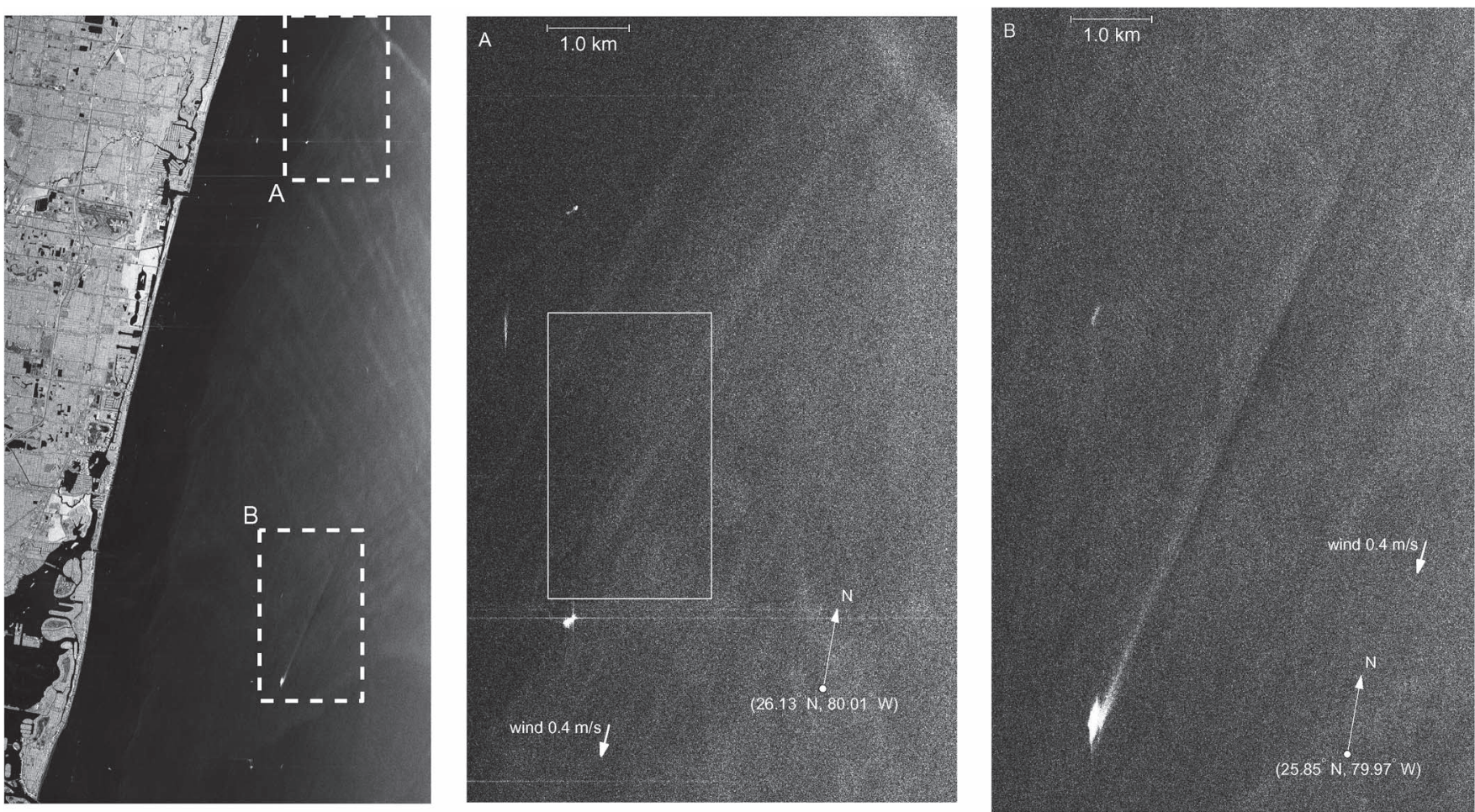

Fig. 7. (Left) SAR image of the Miami area on May 23, 2008. (Center) Clip with the wake of the decelerating ship, Alianca Inca; the rectangle shows the approximate area of sonar measurements. (Right) Clip showing the wake of a steadily moving ship, Xin Su Zhou. All images are in range-azimuth coordinates.

the ship-generated slick and, probably, the wave-breaking zones around it are more pronounced.

\section{Drifting Ship (TSX Polarization HH)}

A wake of a drifting ship is seen on the TSX image of June 25, 2008. The source of the wake, MSC Emma, is a large container ship that is almost $300 \mathrm{~m}$ in length (see Table I), so the westward direction of the wake signature in the SAR image could be explained by screening of wind and waves by the ship's hull (Fig. 9, top panel). This observation is consistent with the easterly wind and southward ship heading during this scene. A wake of the much smaller Caribe Legend (Fig. 9, bottom panel) moving north apparently has both hydrodynamic and "shadow-type" features.

The boat with sonar crossed the shadow-type wake west of MSC Emma (Fig. 9, top panel, rectangle "a") and passed near the ship stern (rectangle "b") while the ship was slowly drifting south. There is practically no acoustic signature of the wake in either case (Fig. 10).

\section{E. Observations of "Shadow-Type" Wakes}

The "shadow-type" ship wakes can be observed in several high-resolution TSX images (see Figs. 9 and 11). It should be noted that these "shadow-type" features are at least as prominent (in terms of size and contrast) as other features of the same wake. We could not find references in the literature to observations of such wakes.

The vector diagrams plotted for Figs. 9 and 11 show that, for the cases studied, the direction of the shadow-type wake is approximately the same as the apparent wind direction for the corresponding ship. The speed of the surface currents is too small to attribute this effect to advection. Of course, more observations of shadow-type wakes are needed to justify these hypotheses.

\section{CONCLUSION}

The factors that control the visibility of ship wakes in SAR and sonar images are related to hydrodynamics, air-bubble dynamics, surface wave dynamics, scattering of electromagnetic waves, and others. The NSUOC-DLR pilot experiment in the Straits of Florida in summer 2008 has resulted in several interesting observations, which may contribute to the development of a comprehensive model of far wakes of ships. The availability of high-resolution SAR imagery from TSX and in situ measurements in ship wakes using a profiling sonar offers a new look at the problem of remote sensing and hydrodynamics of ship wakes.

While the focus of this paper was on finding the correlations between the "visible" (SAR) and underwater appearance of the wake, several potentially important questions, such as the quantitative estimates of the parameters of bubble clouds and the effect of wind and current shear on the sonar and SAR signatures of wakes, have been left beyond the scope of this paper. Additional instrumentation will be required to measure the vertical profiles of near-surface currents, stratification, and to analyze the factors that increase the lifetime of bubbles in ship wakes, including the entrainment of bubbles by large-scale flows in the wake and the coating of bubbles by surfactants [20], [24].

We have presented in the following a few generalizations that could be made from the analysis of the available SAR and sonar data. 

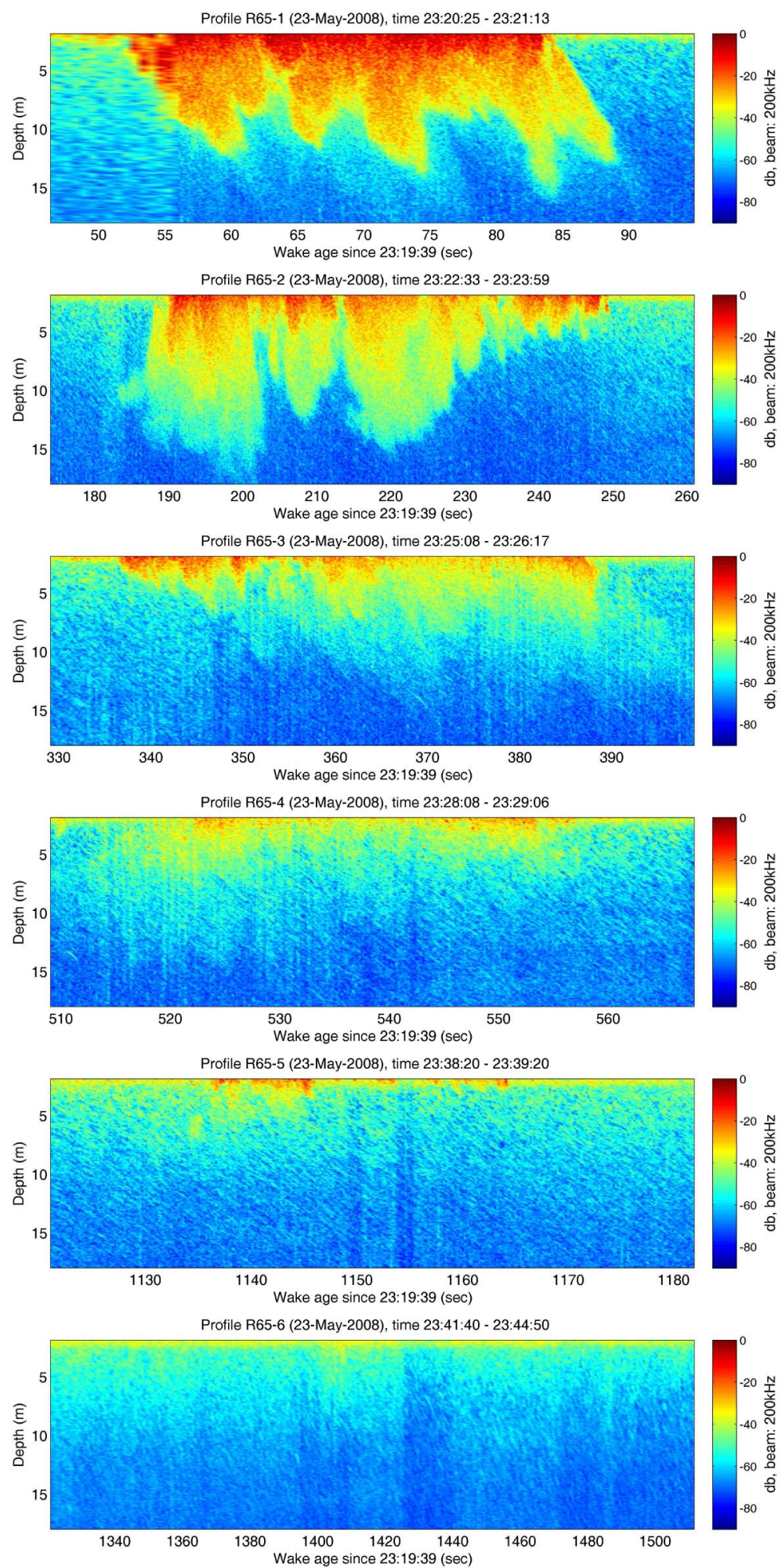

Fig. 8. Six crossings of the wake on May 23, 2008. The boundaries of the wake during the first intersection are tilted, probably due to the ship turning.

1) The length of the centerline wake behind the ship in SAR images appears to correlate with the presence of its hydroacoustic signature. This observation supports the hypothesis that surfactants scavenged from seawater and transported to the surface by bubbles are important for the wake visibility in SAR images.
2) The horizontal patterns of the hydroacoustic and SAR signatures of ship wakes, however, may not exactly coincide. In particular, the asymmetry of ship wakes with respect to wind direction (also observed in photo images) is noticeable in SAR imagery but not in sonar images of the centerline wake area for steadily moving ships. 

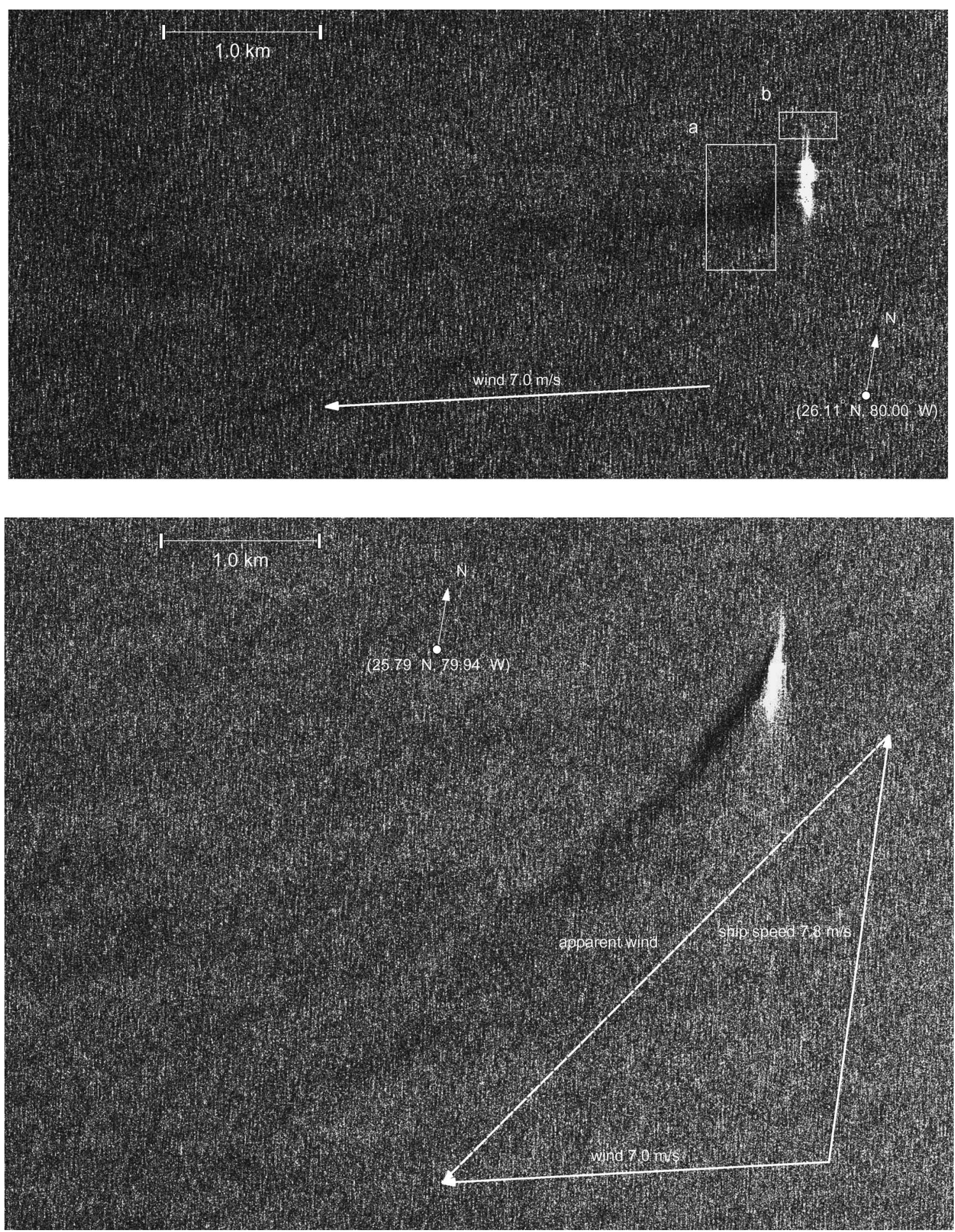

Fig. 9. Clips from the SAR image of the Miami and Port Everglades area made on June 25, 2008. (Top) Wake of MSC Emma due to wind and wave screening; the rectangles show the areas for the sonar data in Fig. 10. (Bottom) Wake of Caribe Legend: The ship is heading north; both its centerline wake (behind the ship) and "shadow-type" wake (skewed astern due to the ship motion) can be seen. The vector diagram shows the direction of the apparent wind.

3) A "shadow-type" wake, which we believe to be a result of screening of the wind-wave field by the ship's hull, is another wake signature that can be seen even in the extreme case of a drifting ship. Although such a wake has no "underwater" part, it may, in some cases, be fairly pronounced in SAR images.

4) SAR-based retrievals of the ship speed and wind field information offer an opportunity for the effective analysis of ship wake dynamics in the open ocean (i.e., outside of the AIS area and away from weather buoys).

Collection of larger statistics from satellite observations and in situ measurements is required for better understanding of ship wake hydrodynamics and further improvement of radar imaging algorithms. These steps are necessary for the 

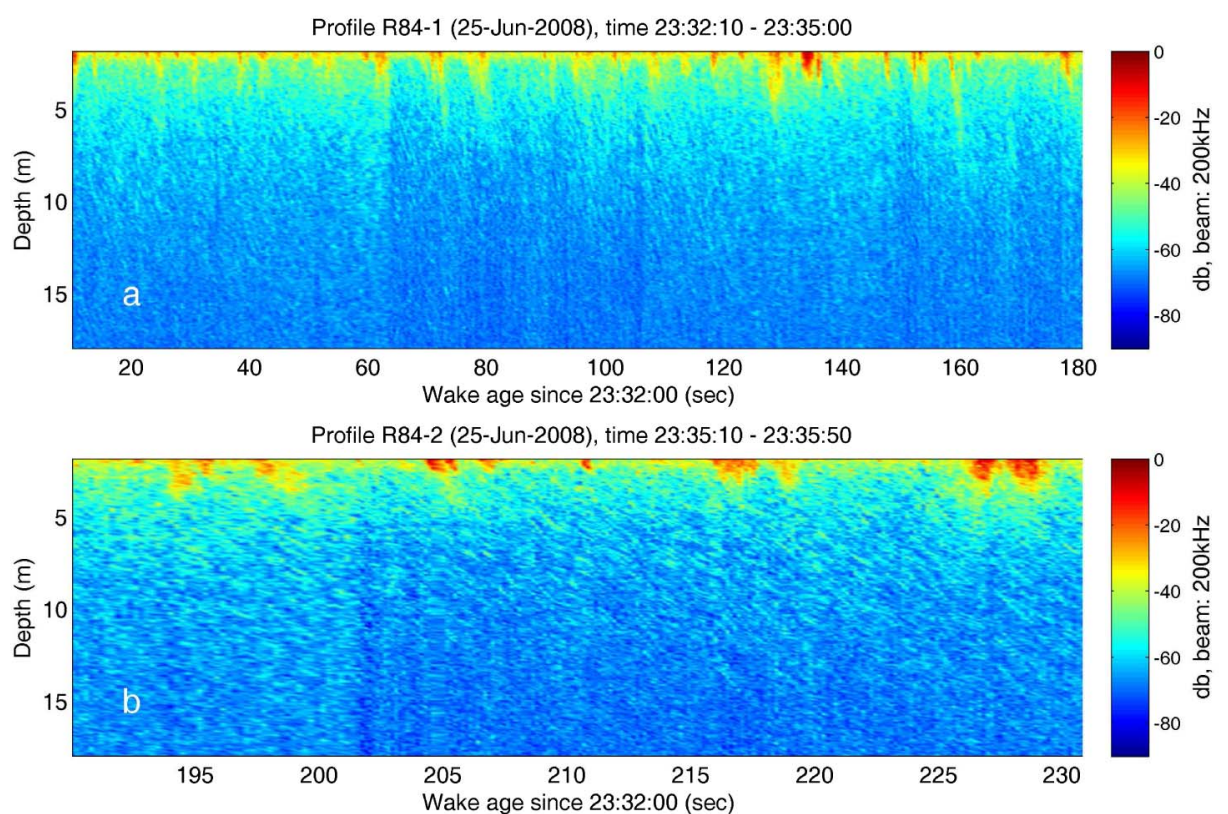

Fig. 10. Sonar return (top panel) downwind and (bottom panel) near the stern of the drifting ship MSC Emma (June 25, 2008)—see the SAR image in Fig. 9 (top panel).

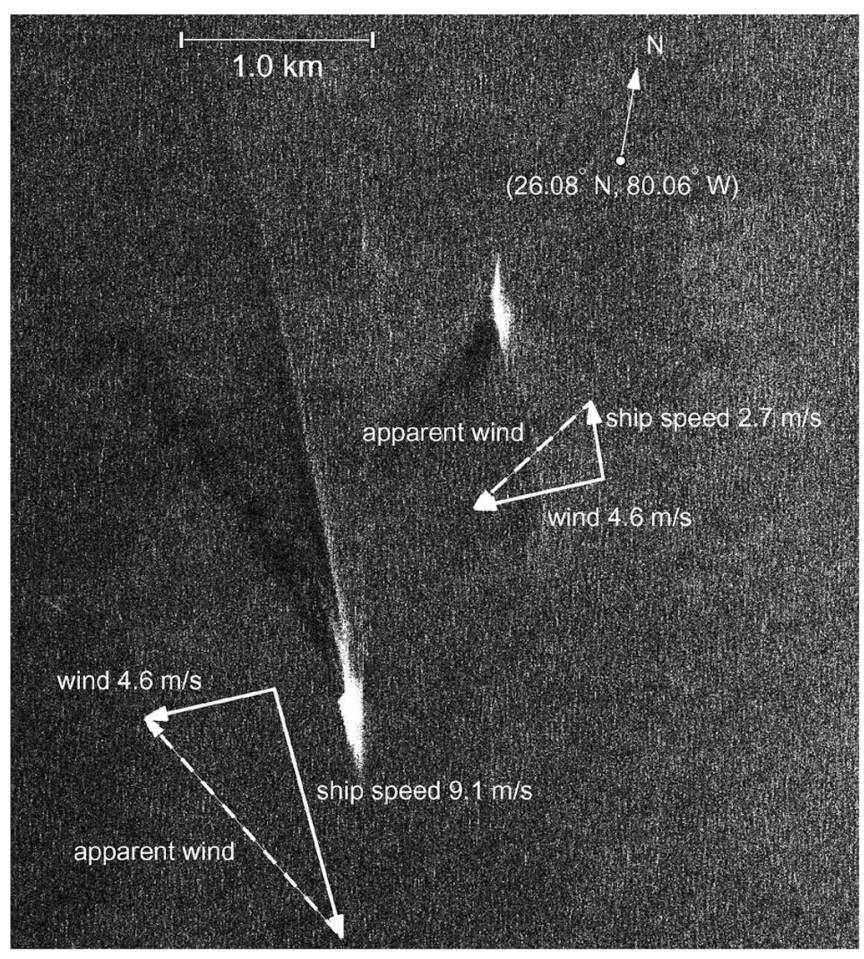

Fig. 11. Clip from the image made on June 14, 2008: The vector diagrams show the direction of the apparent wind coinciding with the direction of the shadow-type wake; the ship on the left is Enchantment of the Seas (notice also the wind asymmetry of its wake); the ship on the right is Dole Colombia.

development of a new generation of remote sensing algorithms for ship and ship wake detection.

\section{ACKNOWLEDGMENT}

The authors would like to thank Dr. E. Keith, Dr. G. Foster, Dr. K. Foster, Capt. L. Robinson, Capt. B. Ettinger, E. Goergen, J. Lueg, and A. Brownlee (all from NSUOC) for the support of the field work; T. Vickers and D. Betts (Humminbird Ma- rine Electronics) and R. Gecy for the help in processing the sonar data; Dr. K. Fisher (Los Alamos National Laboratory) for the fruitful discussion of the results; Dr. S. Purkis and J. Fent (NSUOC) for reading and improving the style of the manuscript; and the anonymous reviewers for the several important corrections that improved the presentation of this paper. The authors appreciated the perfect organization of the 3rd TSX Science Team Meeting, where the preliminary results of this work were presented.

\section{REFERENCES}

[1] L. L. Fu and B. Holt, "Seasat views oceans and sea ice with synthetic aperture radar," NASA JPL Publication, Pasadena, CA, Feb. 15, 1982.

[2] G. Zilman, A. Zapolski, and M. Marom, "The speed and beam of a ship from its wake's SAR images," IEEE Trans. Geosci. Remote Sens., vol. 42, no. 10 , pp. 2335-2343, Oct. 2004.

[3] D. Crisp, "The state-of-the-art in ship detection in synthetic aperture radar imagery," Australian Dept. Defense, Canberra, Australia, 2004.

[4] H. Greidanus and N. Kourti, "Findings of the DECLIMS projectDetection and classification of marine traffic from space," in SEASAR: Advances in SAR Oceanography From Envisat and ERS Missions. Roma, Italy: Eur. Space Agency, 2006.

[5] K. Eldhuset, "An automatic ship and ship wake detection system for spaceborne SAR images in coastal regions," IEEE Trans. Geosci. Remote Sens., vol. 34, no. 4, pp. 1010-1019, Jul. 1996.

[6] A. M. Reed and J. H. Milgram, "Ship wakes and their radar images," Annu. Rev. Fluid Mech., vol. 34, no. 1, pp. 469-502, 2002.

[7] I. Hennings, R. Romeiser, W. Alpers, and A. Viola, "Radar imaging of Kelvin arms of ship wakes," Int. J. Remote Sens., vol. 20, no. 13, pp. 2519-2543, Sep. 1999.

[8] J. H. Milgram, R. A. Skop, R. D. Peltzer, and O. M. Griffin, "Modeling short sea wave energy distribution in the far wakes of ships," J. Geophys. Res., vol. 98, no. C4, pp. 7115-8370, 1993.

[9] R. D. Peltzer, O. M. Griffin, W. R. Barger, and J. A. C. Kaiser, "High-resolution measurement of surface-active film redistribution in ship wakes," J. Geophys. Res., vol. 97, no. C4, pp. 5231-5252, 1992.

[10] T. Wahl, K. Eldhuset, and Å. Skøelv, "Ship traffic monitoring using the ERS-1 SAR," in Proc. 1st ERS-1 Symp., Cannes, France, 1992, pp. 823-828.

[11] A. Soloviev, M. Gilman, K. Moore, K. Young, and H. Graber, "Remote sensing of ship wakes," in SEASAR-2008: Advances in SAR Oceanography From Envisat and ERS Missions. Roma, Italy: Eur. Space Agency, 2008. 
[12] A. Benilov, G. Bang, A. Safray, and I. Tkachenko, "Ship wake detectability in the ocean turbulent environment," in Proc. 23rd Symp. Naval Hydrodynamics, Val de Reuil, France, 2001, pp. 1-15.

[13] M. Trevorrow, High-frequency acoustic scattering and absorption effects within ship wakes, Defence R\&D Canada, Ottawa, ON, Canada. [Online]. Available: http://pubs.drdc.gc.ca/PDFS/unc41/p524260.pdf

[14] S. Stanic, E. Kennedy, B. Brown, D. Medley, R. Goodman, and J. Caruthers, "Broadband acoustic transmission measurements in surface ship wakes," in Proc. Oceans, 2007, pp. 1-10.

[15] P. L. Bergmann and L. Spitzer, Physics of Sound in the Sea. Los Altos, CA: Peninsula, 1946.

[16] S. Brusch, T. Fritz, S. Lehner, A. Soloviev, and B. Schie, "Ship surveillance with TerraSAR-X," IEEE Trans. Geosci. Remote Sens., submitted for publication.

[17] X. Li, S. Lehner, and W. Rosenthal, "Investigation of ocean surface wave refraction using TerraSAR-X data," IEEE Trans. Geosci. Remote Sens., vol. 48, no. 2, pp. 830-840, Feb. 2010.

[18] C. Shen and U. Lemmin, "A new method for probing the turbulence scalar spectrum by ultrasonic sonar scanning," Exp. Fluids, vol. 24, no. 1, pp. 90-92, Jan. 1998.

[19] R. L. Culver and M. F. Trujillo, "Measuring and modeling bubbles in ship wakes, and their effect on acoustic propagation," in Proc. 2nd Int. Conf. Underwater Acoust. Meas.: Technol. Results, Heraklion, Greece, 2007.

[20] T. C. Weber, A. P. Lyons, and D. L. Bradley, "An estimate of the gas transfer rate from oceanic bubbles derived from multibeam sonar observations of a ship wake," J. Geophys. Res., vol. 110, no. C4, p. C04 005, Apr. 2005.

[21] T. Arnesen, R. Olsen, and P. Vachon, "Polarisation-dependent signatures of ships in Envisat AP mode data," in Proc. Envisat ERS Symp., Salzburg, Austria, 2004

[22] J. Yang, W. Huang, Q. Xiao, B. Fu, and L. Yao, "Optimal polarization for the observation of ocean features with SAR," in Proc. Geosci. Remote Sens. Symp., Anchorage, AK, 2004, vol. 5, pp. 3599-3601.

[23] V. Kudryavtsev, D. Akimov, J. Johannessen, and B. Chapron, "On radar imaging of current features: 1 . Model and comparison with observations," J. Geophys. Res., vol. 110, no. C7, pp. C07 016.1-C07 016.27, 2005.

[24] A. W. Lang and M. Gharib, "Experimental study of the wake behind a surface-piercing cylinder for a clean and contaminated free surface," J. Fluid Mech., vol. 402, pp. 109-136, 2000.

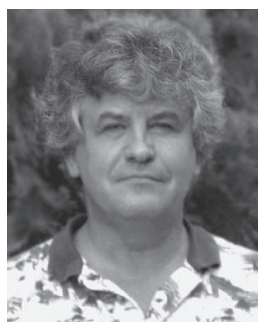

Alexander Soloviev received the M.S. degree in physics from the Moscow Institute of Physics and Technology, Moscow, Russia, in 1976 and the Ph.D. and D.Sc. degrees in physics and mathematics from the former Soviet Academy of Sciences, Moscow, in 1979 and 1992, respectively.

He was a Visiting Scientist with the University of Hawaii, Honolulu, HI, and the University of Hamburg, Hamburg, Germany, and a Scientist in the two leading institutions of the former Soviet Academy of Sciences: P. P. Shirshov Institute of Oceanology and A. M. Oboukhov Institute of Atmospheric Physics. He is currently an Associate Professor with the Oceanographic Center, Nova Southeastern University, Dania Beach, FL. He is also an Adjunct Professor with the Rosenstiel School of Marine and Atmospheric Science, University of Miami, Coral Gables, FL. He has participated in several major oceanographic experiments (POLYMODE, JASIN, FGGE, TOGA COARE, and GASEX) and is the author and coauthor of more than 50 research articles. In coauthorship with Prof. Roger Lukas from the University of Hawaii, he wrote a monograph The Near-Surface Layer of the Ocean: Structure, Dynamics, and Applications (Springer, 2006). His research interests include turbulence and microstructure in the near-surface layer of the ocean, upper ocean boundary layer, bottom boundary layer, remote sensing, biophysical interactions in the ocean, $\mathrm{CO}_{2}$ uptake by the ocean, hurricane physics, coastal ocean circulation, and ocean engineering. His major field of study is physical oceanography.

Dr. Soloviev is a member of the American Geophysical Union and the American Meteorological Society.

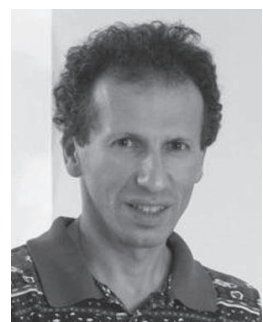

Mikhail Gilman received the M.S. degree in physics from the Moscow Institute of Physics and Technology, Moscow, Russia, in 1987 and the Ph.D. degree from the Russian Academy of Sciences, Moscow, in 1998 .

From 1987 to 2000 with a short break, he was with the Space Research Institute and the Institute for Problems in Mechanics, Russian Academy of Sciences. From 2000 to 2007, he was in software development with the Moscow Center for Continuous Mathematical Education, Moscow. He is currently a Research Scientist with the Oceanographic Center, Nova Southeastern University, Dania Beach, FL. His current research interest is radar oceanography.

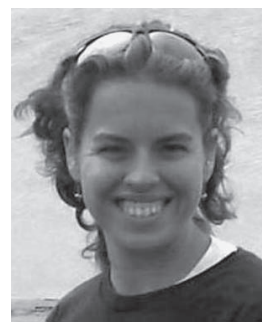

Kathryn Young received the M.S. degree from Nova Southeastern University, Dania Beach, FL, in 2008. She is currently working toward the Ph.D. degree at Baylor University, Waco, TX

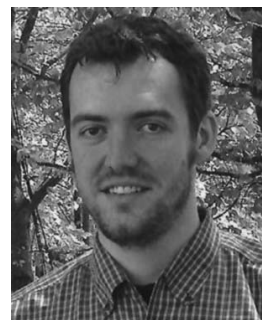

Stephan Brusch received the diploma degree in meteorology from the Free University, Berlin, Germany, in 2006. He is currently pursuing the Ph.D. degree at the Remote Sensing Technology Institute (IMF), DLR. He joined the German Aerospace Center (DLR/DFD), Oberpfaffenhofen, Germany, in 2006. In the framework of the Helmholtz Research Network "Integrated Earth Observing System" Helmholtz-EOS, he is working on SAR observation of ocean waves and wind fields.

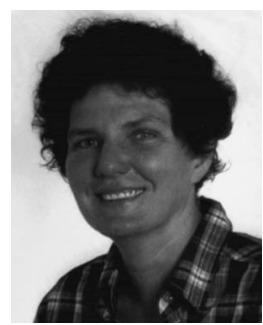

Susanne Lehner received the M.Sc. degree in applied mathematics from Brunel University, Uxbridge, U.K., in 1979, and the Ph.D. degree in geophysics from the University of Hamburg, Hamburg, Germany, in 1984. She was a Research Scientist with the Max-Planck Institute for Climatology, Hamburg, and joined the German Aerospace Center (DLR/DFD), Oberpfaffenhofen, Germany, in 1996. Currently, she is a Research Scientist in marine remote sensing and a head of the Radar Oceanography group at the Remote Sensing Technology Institute (DLR/IFM), Oberpfaffenhofen, Germany, working on the development of algorithms determining marine parameters from SAR. 